\title{
A Concept for Conducting User Studies in Vehicles and Stationary Test Rooms During the COVID-19 Pandemic
}

\author{
Timmy Kantusch ${ }^{1,2^{*}}$, Advan Sinanovic ${ }^{1}$ and Stefanie Marker ${ }^{1}$ \\ 1 Technische Universität Berlin, Faculty V Mechanical Engineering and Transport Systems, Institute of Land and Sea Transport, Chair of \\ Naturalistic Driving Observation for Energetic Optimisation and Accident Avoidance, Straße des 17. Juni 135, 10623 Berlin, Germany; \\ sinanovic@campus.tu-berlin.de (A.S.), stefanie.marker@tu-berlin.de (S.M.) \\ 2 Department of Whole Vehicle Development, Volkswagen AG; Berliner Ring 2, 38440 Wolfsburg, Germany \\ * Correspondence: kantusch@campus.tu-berlin.de
}

\begin{abstract}
The SARS coronavirus 2 pandemic affected many areas of public life and industry. This also applies to research particularly that which relies on user test studies. In order to minimize the risk of infection, several aspects of experiment design including the setting might require alteration. In order to develop a step-by-step approach to plan a study with regard to infection protection, an extensive review of the latest research involving the SARS coronavirus 2 pandemic as a blueprint for dealing with other health situations. As a result, a six-step concept was developed that is applicable for user test studies in both stationary rooms and vehicles which can be adapted to the respective circumstances. The infection protection measures determined through research were implemented in the individual sub-steps from study planning to execution. They allow a step-by-step approach to prevent infections in user test studies during a pandemic and in situations where increased hygiene measures are required, in order to continue to carry out user test studies.
\end{abstract}

Keywords: user studies, pandemic, COVID-19, hygiene concept

\section{Introduction}

Due to the pandemic, triggered by SARS Coronavirus 2 (SARS-CoV-2) in 2019, all areas of daily life are reduced in order protect against infection [1]. This also affects companies and scientific institutions that carry out user test studies, which either cannot take place or must strictly comply with infection protection measures. Therefore, the potential bigger impact of a postponement with the comparatively less effort required to implement infection protection measures has to be taken into account. In order to allow such work to continue, a holistic approach considering pandemic characteristics and indicators with various extensive hygiene measures, can enable subject studies to continue without increasing the risk of infection. For this purpose, an extensive review of recent research was carried out and a concept was developed using the example of the COVID-19 pandemic.

\subsection{SARS-CoV-2}

On December 31st of 2019, Chinese authorities reported the occurrence of a viral pneumonia from the city of Wuhan [2]. This was caused by a novel coronavirus, now known as SARS-CoV-2. The disease, which is triggered after an infection, is called coronavirus disease 19 (COVID-19) [3].

\subsubsection{Background}

SARS-CoV-2 is transmitted mainly from person to person via direct and indirect contact. Direct transmission of viruses in humans takes place mainly through droplet infection (by breathing, speaking, coughing or sneezing) [4] [5]. However, it is also possible via (direct) contact infection [6]. The number of droplets delivered is greatest when coughing and the lowest when breathing. When speaking, six times fewer droplets are given than when coughing, but the number of droplets delivered when speaking depends on volume and pronunciation [7]. 
The aerogenic route of infection describes the transmission of viruses via aerosols and droplet cores. These are either delivered directly by breathing, speaking, coughing or sneezing by humans or are produced as evaporative products of droplets. Mixtures of droplet cores and air are called aerosols [4]. It is assumed that viruses remain infective for about three hours after the evaporation process of the droplets in which they were embedded [8]. If the infectivity persists, infection may occur if virus-containing aerosols and droplet cores are inhaled [4].

The indirect contact infection, or lubrication infection, takes place via the indirect contact of persons. Indirect contact means that although there has been no direct contact between the persons, they have touched the same object or surface one after the other and as a result infection occurs as soon as virus-containing droplets reach the mucous membranes of the upper respiratory tract or the eyes conjunctiva [6] [4]. Viruses are expected to remain active on a surface for up to 72 hours [8]. The average incubation period is five to six days, but can also last up to 14 days [9].

The most common symptoms of COVID-19 include fever, cough, cold and sensory loss of taste or smell [9]. The severity varies widely including a possible symptomless course [10].

People aged 50 and over are particularly susceptible to a difficult disease progression [9]. The so-called risk group also includes people with pre-existing conditions that affect the heart, respiratory system, liver or kidney [11].

Whether a person is immune to the virus can be investigated using so-called antibody tests. On the other hand, an infection with the virus is diagnosed by a so-called polymerase chain reaction test (PCR test). If an immediate result is required, PCR quick tests or self-tests can be performed, but they are less accurate[12].

\subsubsection{Statistical indicators}

The assessment of the epidemiological situation can be implemented using statistical indicators. These allow the analysis of the infectiousness and the danger of the virus causing the epidemic and can also enable conclusions to be drawn about the behavior of the population. Statistical analyses also allow some prediction of the future development of an epidemic, from which infection protection measures can be derived. The main indicators include incidence, prevalence, lethality, mortality rate and the number of reproductions [13] [14].

\subsection{Infection protection measures}

\subsubsection{Maintaining a safe distance}

In the course of the SARS-CoV-2 pandemic, people are recommended to maintain socially distanced, which means at least $1.5 \mathrm{~m}$ apart, as the SARS-CoV-2 is transferable via droplets [15] However, since coughing and sneezing can cause larger droplets to fly farther than $1.5 \mathrm{~m}$ horizontally, keeping a minimum of the recommended distance does not provide $100 \%$ protection from an infected person [16]. The evaporation time of the droplets buttresses the importance of keeping a safe distance from others. In close proximity, droplets can be picked up by a person before they evaporate. The $1.5 \mathrm{~m}$ distance ensures that a large part of the droplets evaporate before reaching another person [16].

Unlike droplets, droplet cores and aerosols do not sink to the ground on a ballistic track, but move with the air. Due to this movement, infection is also possible beyond a distance of $1.5 \mathrm{~m}$. This is especially true for longer stays in rooms with poor ventilation. Therefore, further antiviral measures must be taken, especially in enclosed premises, in order to minimize the risk of infection [8]. Outdoors, the probability of aerogenic infection is significantly lower, but a safe distance of at least $1.5 \mathrm{~m}$ between individuals is recommended, as

despite all environmental conditions, the flight distance and evaporation time of droplets, may be similar to those occurring in enclosed spaces [16] [8].

In order to prevent direct contact infections, it is also important to remain distant. For example, welcome rituals, such as shaking hands or hugging, should not happen. However, indirect contact infections cannot be prevented by maintaining safe distances alone [15]. 


\subsubsection{Protective masks}

In addition to social distancing, the correct wearing of protective masks is also considered to be one of the most important measures to prevent infections of airborne viruses. Wearing protective masks is especially important indoors and in situations where safe distance to others cannot be maintained [17]. The primary function of a respiratory mask is the external protection, however, masks also offer limited selfprotection against droplet infections secondarily [18]. Since the eyes are an entry point for disease transmission, protective goggles with a respiratory mask is warranted [4]. Unfortunately, these masks offer neither self nor external protection against infectious aerosols and droplet cores. Due to their movement with the air, such virus-laden particles flow past the edges of the mouth and between the skin and mask, thus escaping into the ambient air. Aerosols and droplet cores can also be inhaled via the leaking spots on the side edges, leading to infection. Wearing a respiratory mask not only protects against droplet infections, but also partly against direct and indirect contactinfection by minimizing access to the mouth and nose[19]. By fitting closely on the human face, FFP2 (Filtering Face Piece) to FFP3 masks offer comparatively high protection against droplet and aerogenic infections than othermasks including surgical ones [4].

\subsubsection{Ventilation}

Aerosols and droplet cores, in contrast to droplets, follow the movement of indoor air. Their movement in enclosed spaces is also dependent on heat sources, ventilation and the movement of persons and objects in the room [8]. Aerosols and droplet cores are able to fully distribute in a room [20], so that infections can occur despite social distancing [4]. The concentration of aerosols and droplet cores in the air depends on a number of factors: the number of people present, their activities and total time in the room as well as the room's size and ventilation. [21].

A study by Kriegel [20] demonstrates that the concentration of infectious particles increases the longer an infected person is in an unventilated room. The number of infectious particles increases significantly more in a smaller room than in a larger room. At the same time, the number of indented particles loaded by viruses increases exponentially. Through ventilation, the concentration of infectious particles can be significantly reduced. Here the air change rate, i. e. the time period in which the room air is exchanged for fresh air [22], plays a role. Even a rate of 2.8 air changes per hour leads to a significantly lower number of infectious particles in the room and decreases further with a higher air change rate. The number of indented particles loaded with viruses also decreases significantly through an increased rate of air change and avoids the exponential growth found in an unventilated room.

\subsubsection{Hygiene}

Another important infection protection measure is proper hygiene [23], particularly keeping hands clean through washing or disinfection, which contributes to the prevention of both direct and indirect contact infection [24]. Hands should be washed before and after wearing protective masks, before and after contact with other persons or surfaces, and after sneezing and coughing [23]. If hand washing is not possible, hand sanitizer should be used. The prevention of droplet infections as well as those transmitted through indirect and direct contact requires coughs and sneezes to be covered [23]. In order to avoid indirect contact infections via contaminated objects and surfaces, they must be cleaned and disinfected before and after each subject [23] [25] [26].

\subsubsection{Contact restrictions and tracking}

The best way to prevent infection with an airborne virus is to avoid contact with other people through measures like a quarantine. Over long periods of time some contact with others is unavoidable. Therefore, 
contact tracing is an important measure to break infection chains. This tracking identifies contact persons of a demonstrably infected person [27].

\subsection{Aspects for infection protection measures in a vehicle}

\subsubsection{Infection routes}

Studies in vehicles require special measures. A study by Makoto [28] for simulations of droplet and aerosol spread in a room shows that conversations between two people sitting in close proximity increase the risk of infection. The study also shows that if they can't pick up drops directly from the air if they do not face each other while speaking.

Another study by Makoto [29] simulates the distribution of aerosols and droplet cores in the air of an unventilated vehicle. It established that aerosols and droplet cores are distributed almost homogeneously in the entire interior air of the vehicle very quickly. Due to the low interior volume of vehicles, the concentration of aerosols and droplet cores increases faster than indoors, which can lead to an aerogenic infection even after a short exposure.

\subsubsection{Mainting a safe distance in a vehicle}

Due to the geometric properties of the interior of a vehicle, it is usually not possible to maintain a recommended distance of at least $1.5 \mathrm{~m}$ between the driver and the passenger [30]. Based on trigonometric calculations, this distance can only be achieved in a diagonal seating arrangement if there are no more than two persons in the vehicle [31].

\subsubsection{Protective Barriers}

To prevent viral infections in vehicles, it is recommended to attach partitions that can fully prevent both direct contact and droplet infections while limiting aerogenic infections [26]. Such protective walls can be installed, either as a barrier between the front and rear part of the vehicle, or between the driver and the passenger.

A study by Makoto [29] shows the distribution of aerosols and droplet cores in a vehicle three seconds after the driver coughs with a slightly open window on the driver's side and built-in partition wall. It is clear from this that a partition successfully avoids a homogeneous distribution of the particles, as they remain mostly in the front area of the vehicle. Most aerosols and droplet cores that enter the rear of the vehicle flow with the air below the protective wall. A slightly open window can also allow many particles to escape from the vehicle.

\subsubsection{Ventilation}

Just like in stationary venues, ventilation of the vehicle interior can prevent aerogenic infections [29]. Due to the much lower volume, however, significantly higher air exchange rates can be achieved in vehicles. Depending on the type of ventilation, the volume of the interior, the number of occupants in the vehicle and the speed of the vehicle, the air in the interior of the vehicle can be replaced for fresh air more than 300 times per hour. Three fresh air supply strategies can be used: the fresh machine supply, the opening of the windows or the combination of both methods [32].

In a study by Mathai et al. [32] it is shown, that opening the windows has a positive effect on the air exchange rate which can be further improved by increasing vehicle speed. The more windows are opened, the higher the infection protection.

The mechanical supply of fresh air also has a positive effect on the air change rate as shown in a study by Fruin et al. [33]. At a higher setting of the ventilation system, the air exchange rate increases. This principle also applies to stationary vehicles. A study by Knibbs et al. [34] confirms this as the risk of infection decreases with the ventilation system switched on while driving at an increased speed. 


\section{Materials and Methods}

A comprehensive analysis of pandemic research lead to the development of a concept for conducting subject studies during the COVID-19 pandemic. Both research on virology and infection prevention before and after the start of the COVID-19 pandemic were considered to develop a concept applicable to studies in vehicles and stationary facilities. The concept provides a step-by-step approach in the form of a flowchart, created using the software Microsoft Visio 2016 and Lucidchart and the floor plans were created using Vectorworks Educational Version 2021.

\section{Results}

Using fundamental principles, this holistic concept can be used to prevent infections caused by a viral pathogen in subject studies (Figure 1). Additionally, the proposed six-step concept can be tailored to different study settings.

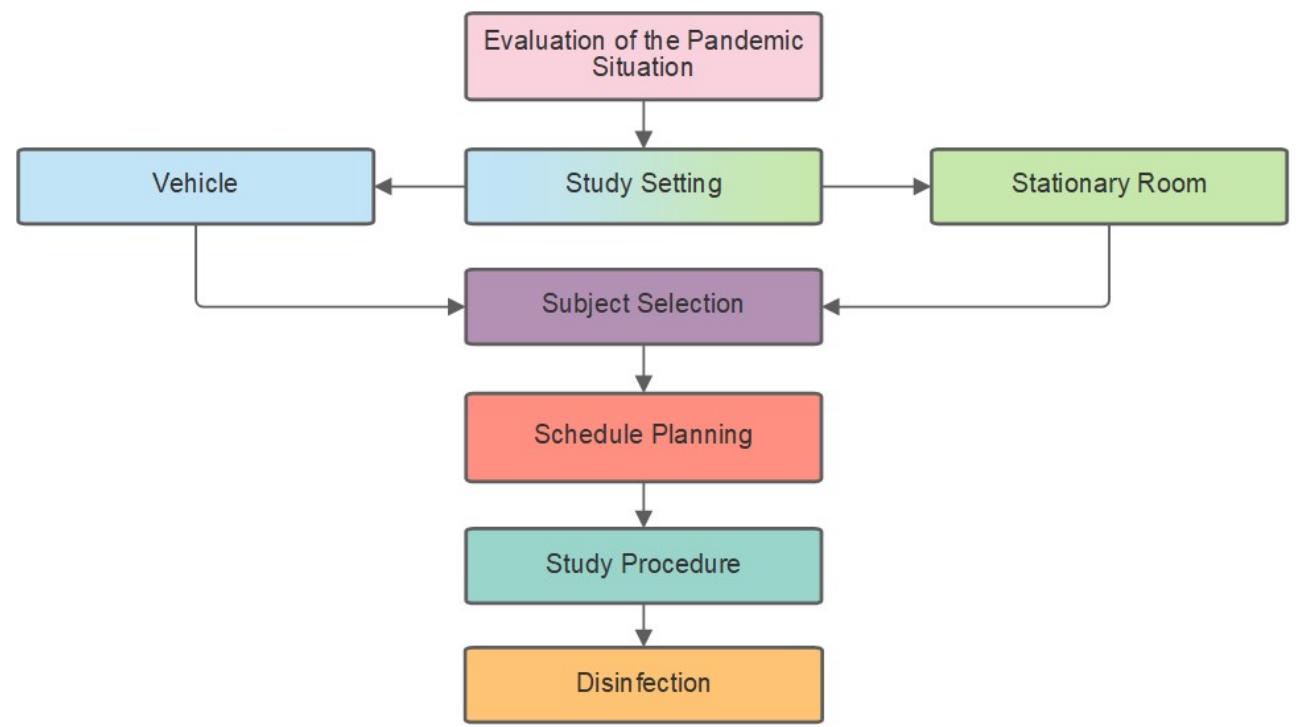

Figure 1. Holistic concept for infection prevention in studies conducted in stationary rooms and vehicles.

The concept includes the relevant steps for planning and conducting a subject study using the example of the COVID-19 pandemic. However, this concept can also be used for other pandemics or situations where comprehensive hygiene measures are required. For the concept we focused on subject studies conducted in stationary rooms and vehicles.

\subsection{Evaluation of the pandemic situation}

Before a study can be conducted during a pandemic, the current situation including various aspects of the pathogen must first be evaluated in order to decide whether such a study is justifiable (Figure 2). 


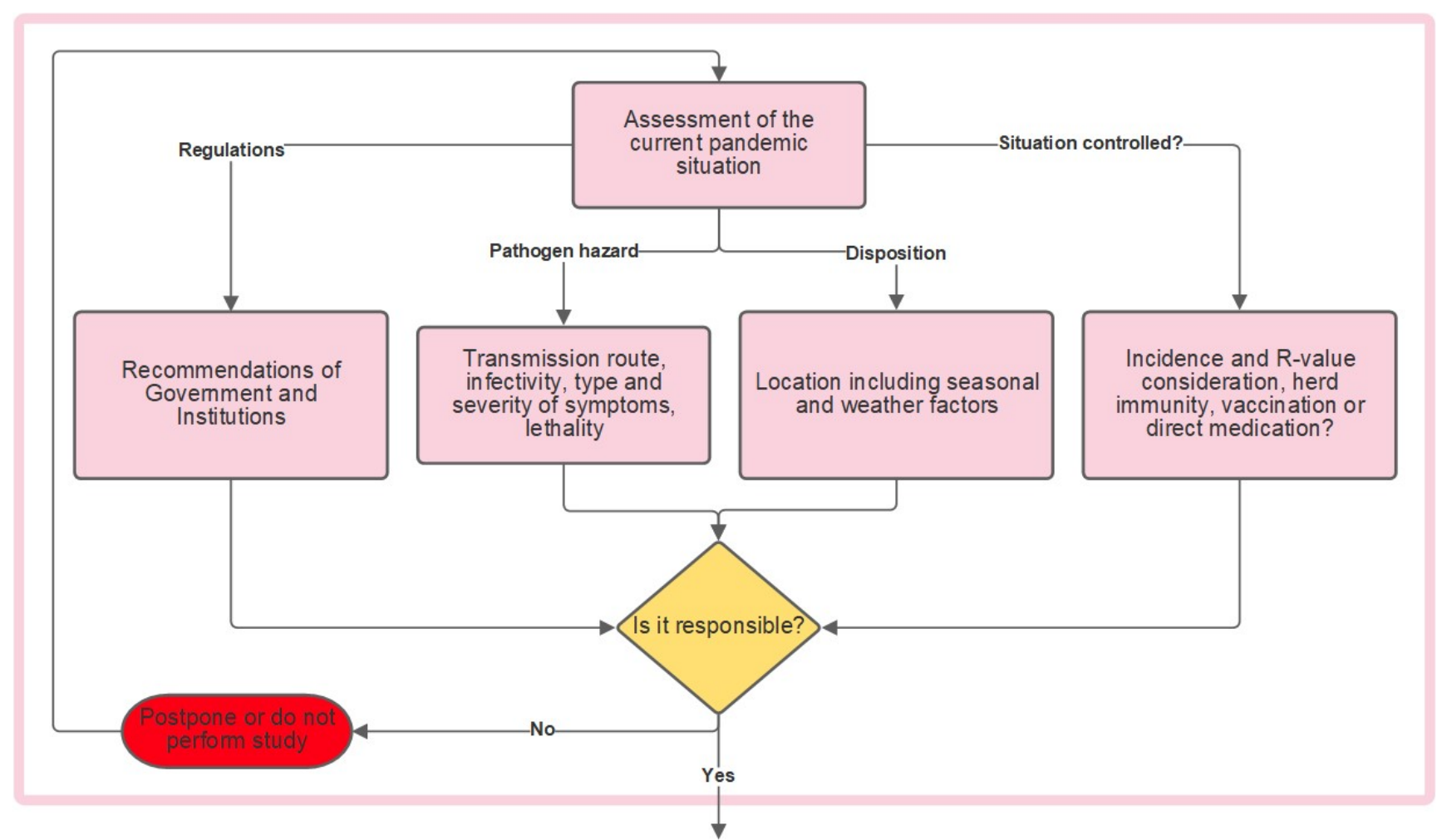

Figure 2. Evaluation of the pandemic situation.

For this purpose, it is advisable to first consider the recommendations of the responsible authorities and institutions. It is possible that after this step, a postponement of the study is the only responsible course of action. Absent that determination or if only minor measures are officially recommended, an independent qualitative risk evaluation should be conducted.

\subsubsection{Pathogen hazard}

When assessing the pandemic situation independently, the pathogen should be considered first. If the pathogen is transmitted via vectors, water or food, the studies should be feasible without any problems, since no infections can be caused by the study. If the pathogen is transmitted via direct or indirect human-tohuman contact, infections may occur during the study. Therefore, other factors must be considered. For instance, if a very high viral load is required for infection, meaning an infection is only possible at all after a long exposure time, the study can be adjusted so that the study time is less than the exposure time required for infection. If the pathogen is moderately to highly infectious, the likely course of illness must be considered. If severe health consequences are expected, or if the lethality rate is particularly high, it may not be responsible to conduct the study. In cases where the pathogen is only dangerous for certain types of people, than these populations can and must be excluded.

\subsubsection{Disposition}

Dispositions that are particularly conducive to infection must be avoided. During a pandemic, studies should be limited to summertime, as viral infections are more likely to happen in the cold winter months [35]. Pathogen-specific disposition conditions should be analyzed in order to be able to avoid them accordingly. 


\subsubsection{Situation controlled?}

Statistical indicators can be used to assess the current and future pandemic situation. For instance, a snapshot of current indicators including incidence, seven-day incidence rate and reproduction rate of the virus should be consulted. If the incidence rate exceeds a value of 35 new infections per 100,000 inhabitants, an in-person study, depending on the pathogen characteristics, could no longer be responsible. At an incidence rate above 50 new infections per 100,000 inhabitants or a reproduction rate above 1, the ability to responsibly conduct a study is very unlikely.

How and to what extent a disease is treatable should also be considered. If suitable and effective antiviral therapies are available, then conducting studies with test persons can be justifiable, since serious consequences of the disease can be avoided in spite of possible infections. If many people have already been vaccinated against the pathogen or if within the population there is a natural immunity, conduct studies in person can be considered more responsible than at other times during a pandemic.

\subsection{Infection protection measures - Stationary test rooms}

In order to use a stationary indoor facility, appropriate infection protection measures have to be implemented in advance (Figure 3). These include the required hygiene measures and a preliminary examination of the test person. Only after this exam should the subjects enter the actual trial. Respiratory masks have to be worn at all times. This ventilation concept applies also to vehicles (Chapter 3.3.).

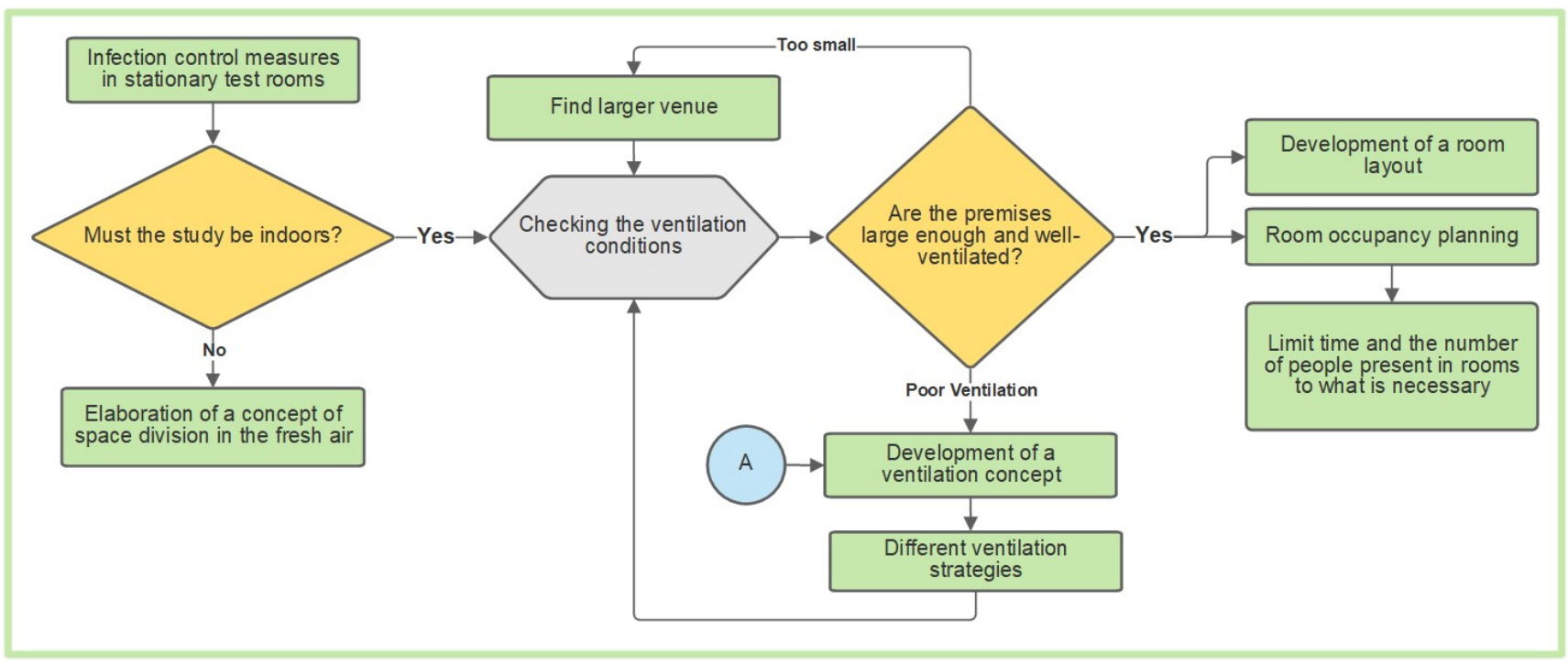

Figure 3. Infection control measures in stationary test rooms.

\subsubsection{Stationary test rooms - Ventilation conditions}

When planning in-person studies, it must first be clarified whether it must be held indoors. If so, it is imperative to check the ventilation conditions in the rooms. It must be confirmed that six air changes per hour can be achieved in all rooms that are to be used and that the relative humidity between $40 \%$ and $60 \%$ can be maintained. To control the relative humidity, it is recommended to use air humidifiers and dehumidifiers, which ensure the optimum relative humidity in the room. Optimally, room temperature can be kept to a constant $20^{\circ} \mathrm{C}$. Additionally, the level of carbon dioxide in the rooms must be monitored. The amount of time until 1000 ppm limit is reached should be tested in advance. The latter [15] test can aid in a room size evaluation. If the critical carbon dioxide concentration is reached too quickly, this may indicate that the rooms are too small. If the carbon dioxide concentration is too difficult to regulate with common ventilation methods, larger rooms must be found. If the required humidity and air exchange rate cannot be 
maintained, a ventilation concept must be worked out for the rooms. If windows are present, this should take into account shock ventilation. Care must be taken to ensure that the rooms do not cool down, since the temperature difference between the room and the environment will lead to room air escaping through the windows. In order to monitor the air quality as well as the number of aerosols and droplet cores in a room, devices can also be used to measure the carbon dioxide concentration in the room air. Carbon dioxide is a released byproduct in all processes involving the release of aerosols and droplet cores [36]. Therefore, the amount of potentially infectious particles in the air is closely linked to the carbon dioxide concentration. For rooms with windows but without a ventilation system, timely regular intervals of ventilation can be calculated in advance.

To achieve the required air exchange rates, the use of mechanical ventilation systems is recommended. For this purpose, central ventilation systems can be installed in the rooms. However, the effectiveness of such ventilation systems comes at a high financial cost. If mechanical ventilation systems are used, it must be noted that vertical air movements should be avoided and that displacement ventilation systems are therefore particularly suitable for ventilating stationary rooms.

Displacement ventilation is recommended. With this method spring vents are installed near the ground, so that the usually colder fresh air accumulates at the bottom of a room. This air then climbs up to heat sources towards the ceiling, where it is extracted. Aerosols and droplet cores also rise with the convection flow and are sucked out, making aerogenic infections less likely [8].

If adjusting ventilation settings, it must be rechecked. Therefore, once perfect ventilation has been achieved, the rest of the study planning can proceed.

\subsubsection{Stationary test rooms - room occupancy planning}

If the room size and ventilation is satisfactory, planning occupancy and layout must serve to maintain safe distances and avoid crowding in the room. The goal of planning the room layout should be to minimize the number of people in the room while factoring in the time present. This can be done in advance through scheduling. Additionally, lists can be maintained, in which each person must enter their name, entry and exit time, in order to simplify any contact tracking that may become necessary.

The first step of planning the room layout is a hygienic cleaning and a preliminary examination. Waiting areas for test subjects as well as break areas for the test administration are required. If the actual study takes place in a simulator, the experimental room must be separate. The walking paths and directions of the test subjects must be clearly marked. In order to limit encounters, the testing rooms should have separate entrances and exits. Similarly, the walking paths to and from the rooms should be separated. This ensures that safe distances are maintained even in narrow corridors. An ideal room layout is shown in Figure 4 . It includes a room for reception with hygienic measures, a room for the preliminary examination, as well as a break room for the administration and a test room. 

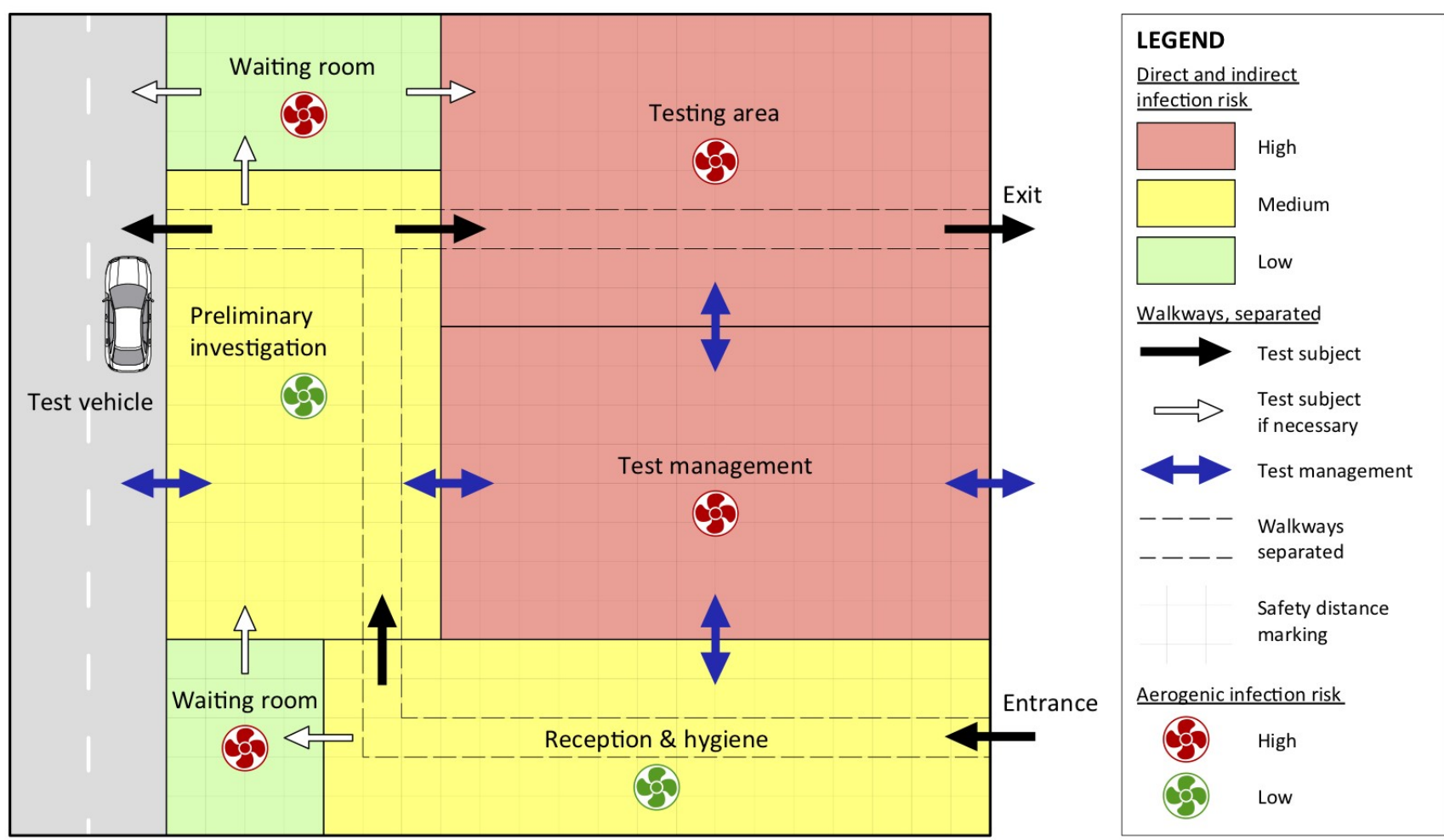

Figure 4. Indoor floor plan example for conducting a study in a room or vehicle.

The walking routes of the subjects are shown with black and white arrows, while the walking routes of the test administration are marked with blue arrows. Since the investigators have to enter each room, their entry and exit is not restricted. The subjects, however, can only move from entrance to exit in the direction shown. In addition, Figure 4 shows the relative risk of infection by the color of the room. The waiting rooms have a low risk (green) of direct or indirect contact or droplet infection, since only one volunteer can be in the waiting room at a given time. Rooms colored yellow have a medium risk of infection, as two people are present in these rooms at the same time. Red rooms, such as the experimental room and the management's common area, have a high risk of infection, since at least two people are present in these rooms for a longer time. In the rooms marked in yellow and red, it is therefore particularly important to pay attention to the basic infection protection measures (e. g. safe distance, respiratory mask, hygiene).

Additionally, a green or red rotor symbol represents the risk of aerogenic infection. A green rotor symbol, as seen in the reception or hygiene rooms, denotes a low risk of infection due to aerosol exposure. These rooms as well as the pre-examination room, are only used for short time periods. In all other rooms, a high risk of aerogenic infections is symbolized by the red rotor, as several people may be present in these rooms for longer periods of time. While waiting rooms are occupied by only one person at a time, they are assumed to be small with a typically longer duration. In these rooms, the air conditions must be closely monitored.

Room dividers can separate larger rooms into smaller ones to improve layout conditions. Therefore, it may be possible to use buildings with suboptimal layouts for the purpose of the study.

In order to maintain safe distances in stationary rooms, markings can be placed on the floor, which are at least $1.5 \mathrm{~m}$ apart. If the entire floor of the room is divided into a grid, the people in a room can easily maintain the required distance. No more than one person stands in a square measuring $1.5 \mathrm{~m} \times 1.5 \mathrm{~m}$, and the adjacent square is kept empty to maintain a distance between the two individuals. This is illustrated in Figure 5, where two people occupy a room divided into 30 sections. 


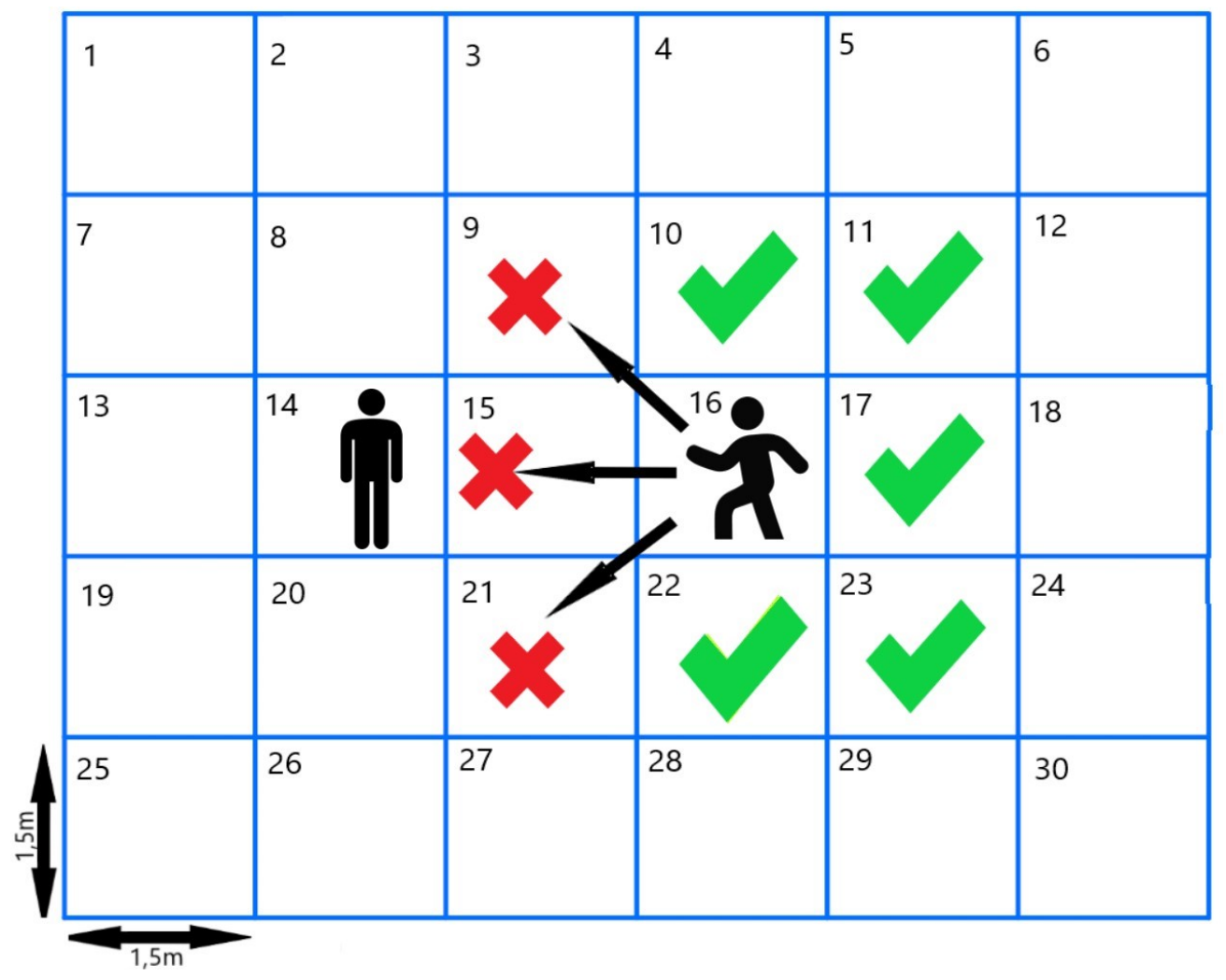

Figure 5. Markings on the floor to maintain a safe distance.

One person stands in section 14, the other in 16. Since section 15 is located between them, it can be seen at first glance that the necessary safe distance is maintained. When one person is stationary, then no one else may enter the sections 21,25 or 9 . However, if someone moves into these squares, the other person must move back. In order for the person on the right to enter section 15, the person on the left would have to have moved to 13 beforehand.

If not absolutely necessary to enter the test rooms, hygienic measures and the preliminary examination should take place outdoors. This eliminates the possibility of aerogenic infections passing between the test administration and the test subjects. In order to conduct these first activities outdoors, an area allocation concept including the use of triage or fixed tents needs to be developed. Such tents can serve as a waiting area for the test subjects between the first measures and the actual experiment. The walking routes of the subjects as well as the individual stations must be clearly marked and distinguishable, so that they always remain in designated areas. Furthermore, clearly marked entrances and exits must be provided. Such a concept is shown in Figure 6. 

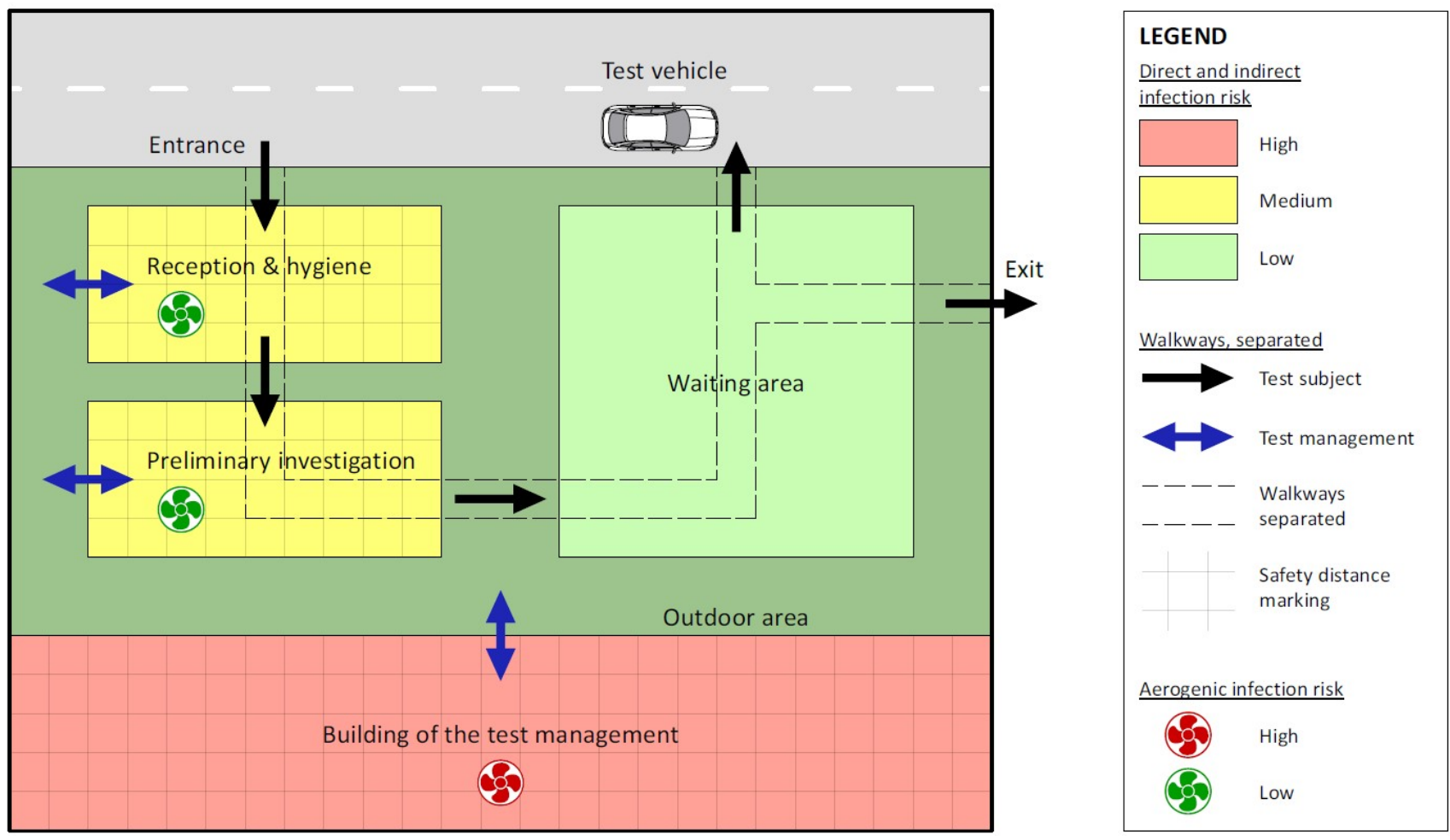

Figure 6. Outdoor area plan for conducting a study using a vehicle.

Just as in Figure 4, the infection risks are also estimated. In the tents for reception, hygiene and preliminary examinations, a medium risk of infection via direct and indirect contact as well as droplets is to be expected, since two persons must interact in these rooms despite all infection protection measures. In the waiting area, there is a low risk of infection because no other person is present at the same time as the test person. Aerogenic infections can also be ruled out in the waiting area, since all aerosols emitted by the subjects escape directly into the environment. In the triage tents aerogenic infections cannot be completely excluded, but such kind of infections are not to be expected here, as they can be well prevented with air purification devices. In addition, large amounts of fresh air can enter the triage tents from outside due to wind, if the tent structure allows air exchange or one side of the tent is raised for a short time. A high risk of infection is expected within the building of the test management, since at least two people of the staff could be present in these rooms for a longer time.

\subsection{Infection protection measures - vehicle}

In order to carry out a test subject study in a vehicle, special aspects must be taken into account, which are shown in Figure 7. In particular, the vehicle as a comparatively small room and ventilation conditions play a decisive role in comparison to stationary test rooms. It is necessary that both occupants wear a respirator mask during the entire test. The respirators worn should be at least FFP2 standard, so that both self-protection and protection from others are ensured. If it is not possible for the person driving to wear a respirator due to the study conditions, special care must be taken to ensure that as little as possible is spoken during the test in order to minimize the number of aerosols and droplets emitted and that the mentioned partition wall is installed. 


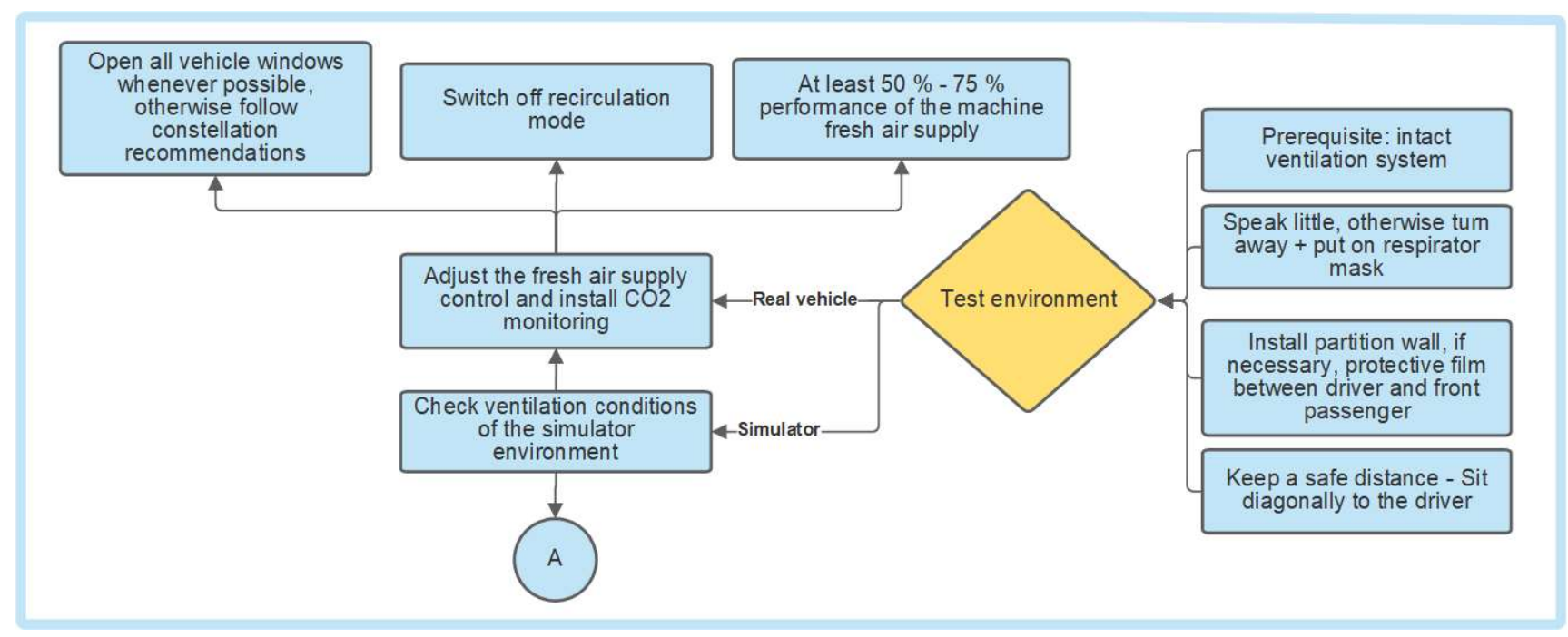

Figure 7. Infection control measures in vehicles and simulators.

\subsubsection{Vehicle occupancy}

In order to determine the requirement for infection control measures in the study vehicle, it must first be clarified whether a person conducting the test must be present in the vehicle in addition to the test subjects. If the test subjects can be monitored by cameras or if only the acquisition of sensory data is important, which can also be evaluated after the execution of the individual driving tests and therefore, no supervisor must be present in the vehicle during the test and no infection control measures are required during the execution of the actual test. Since there is only one person in the vehicle, no person can infect the other with a pathogen via aerosols and droplets or direct contact. To prevent indirect contact infections and aerogenic infections afterwards between the test subjects, disinfection is required and the vehicle must be aired out. The general recommended infection control measures must be followed before and after the experiment.

If a supervisor must be present in the vehicle during the test drive, then a number of infection control measures are required. First of all, the safety distance to the driver-subject must be maintained. Therefore, the supervisor should sit in the right rear seat. Only one subject is allowed in the car at a time, otherwise the safe distances will be inadequate. Furthermore, a transparent partition must be installed between the supervisor and the subject. Depending on the study setting, this would either separate the front and the rear seats or the driver and passenger seats.

\subsubsection{Ventilation in a vehicle}

The test vehicle requires a working ventilation system. Here a distinction must be made between tests in real vehicles and simulators. While unlimited fresh air is available in real vehicle studies, the simulator will depend on the ventilation conditions in the room where it is located. If the study is carried out in a real vehicle, the fresh air supply must be set correctly before the start of the test. The recirculation mode of the ventilation system cannot be used. If possible, at least $50 \%$ of the maximum output of the vehicle's mechanical fresh air supply should be used, so that at least 60 air changes per hour take place. While in motion, all vehicle windows are to be open whenever possible in order to maximize air exchange rates in the vehicle. If this is not possible, the recommended constellation for open windows should be followed as described in chapter 1.3.4. Opening the windows is particularly recommended at speeds above $10 \mathrm{~m} / \mathrm{s}$. A carbon dioxide monitor should also be installed in the vehicle. If this rises above $1000 \mathrm{ppm}$ during the test, it is imperative to increase the output of the mechanical fresh air supply or to open more windows.

If the study is carried out with the help of a simulator, a ventilation concept according to the example for stationary rooms should be employed. If a ventilation system is present in the simulator, $50 \%$ to $75 \%$ of 
the maximum output is necessary just as in the real vehicle. This serves to protect against aerogenic infections in the simulator. With the help of additional ventilation in the simulator, potentially contaminated air is released into the air, where it is removed or cleaned. Additionally, air must move between the simulator and the room. Otherwise no fresh air will enter the simulator, causing the risk of infection to increase rapidly over time. Although this is only of concern if more than one person is in the simulator.

\subsection{Subject selection}

Most importantly, at-risk individuals are not invited to the study (Figure 8). The risk group classification should be used. For the SARS-CoV-2 pandemic, elderly and previously ill people would be excluded from the study. Furthermore, people working in health care or who have direct contact with patients or risk groups for other reasons, should also be excluded from the study, as they are at an increased risk of being infected or infecting people in the risk groups. People who live in or have recently traveled to a high-risk region should also be excluded. Preference therefore should be given to individuals expected to have a less severe course of disease following infection with the pathogen. During the SARS-CoV-2 pandemic, for example, these would be younger and healthy people. Immunized individuals, with proof in the form of a certificate or antibody testing should also be targeted for the study. Those individuals who are willing to quarantine voluntarily in advance of the study and for the maximum incubation period of the pathogen, may also be given priority for invitation to the study. If they do not experience any symptoms of the disease caused by the pathogen during quarantine, it can be assumed that the quarantined individuals will not cause any infections during the study. The only possibility of infection is in transit from the place of residence to the study site. This risk can be mitigated further by the subject using their private car or travelling on foot. The likelihood of these individuals infecting someone during the study is considered as low, so a voluntary quarantine of study participants can be a welcome infection control measure when conducting studies. 


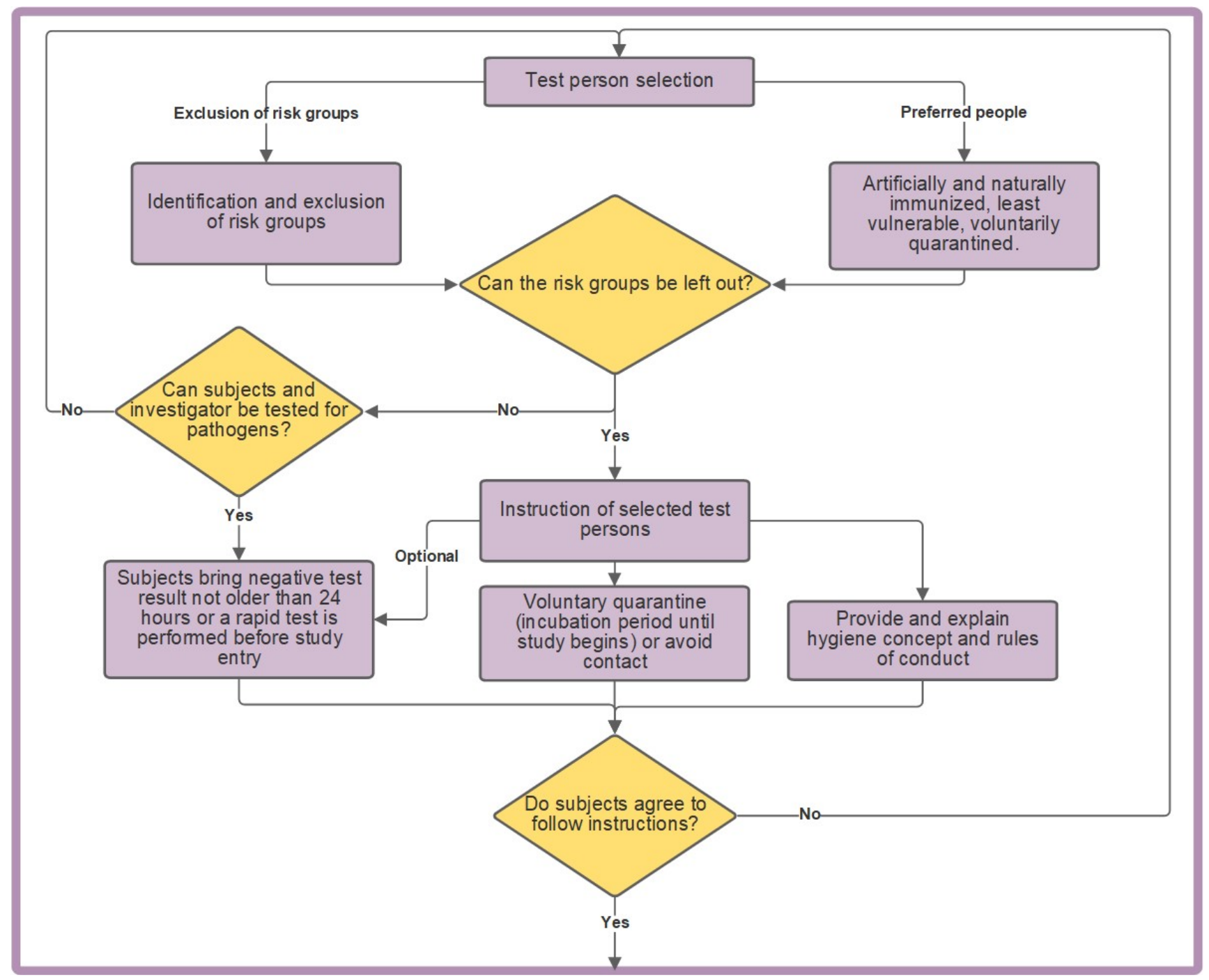

Figure 8. Subject selection.

Furthermore, it must be decided whether the study can be conducted without the individuals who need to be excluded. For example, if the elderly must be excluded, then it becomes difficult to accomplish a representative cross-section of the population. If this goal is a priority, then it must be determined whether the subjects and investigators can be tested for the pathogen. If all persons on site can show a negative test result, infections can be excluded. As for SARS-CoV-2, either a PCR laboratory test or a PCR rapid test administered at the study site would have to be performed prior to starting the study. The problem with the PCR laboratory test is that it says nothing about the possible infection of the subjects and investigators at the time of the study. It only represents the situation at the time of testing, which can be several hours or days ago. Preferably, a PCR rapid test should be performed shortly before the start of the study at the study site. If the test is positive or unclear, the tested person is not allowed to participate in the study.

Members of risk groups can participate in the study if and only if every person involved in the study can be tested for the pathogen. If it is not possible to test all persons involved for the pathogen, then the risk group members cannot participate. Therefore, the study must be postponed. If members of risk groups are excluded from participation, then testing for subjects and investigators can be optional. It is better to test all subjects for the pathogen, since this benefits the study overall, as infections can almost be eliminated.

Once the waiver and test process has been clarified, the selected subjects must be informed about the study procedure and the hygiene concept that awaits them on site. In addition, the selected subjects must be 
informed that they should avoid contact with other people before the start of the study. In advance, the subjects have to agree to follow the instructions.

\subsection{Conducting the study}

The following chapter consists of the schedule and study procedure (Figure 9). The scheduling takes place before the actual start of the study and ensures an organized test process. The conduction of the study is divided into the subjects of reception, preliminary examination and the actual study. Reception and preliminary examination are necessary in order not to allow infected subjects to enter the study and to implement and communicate initial hygiene measures.

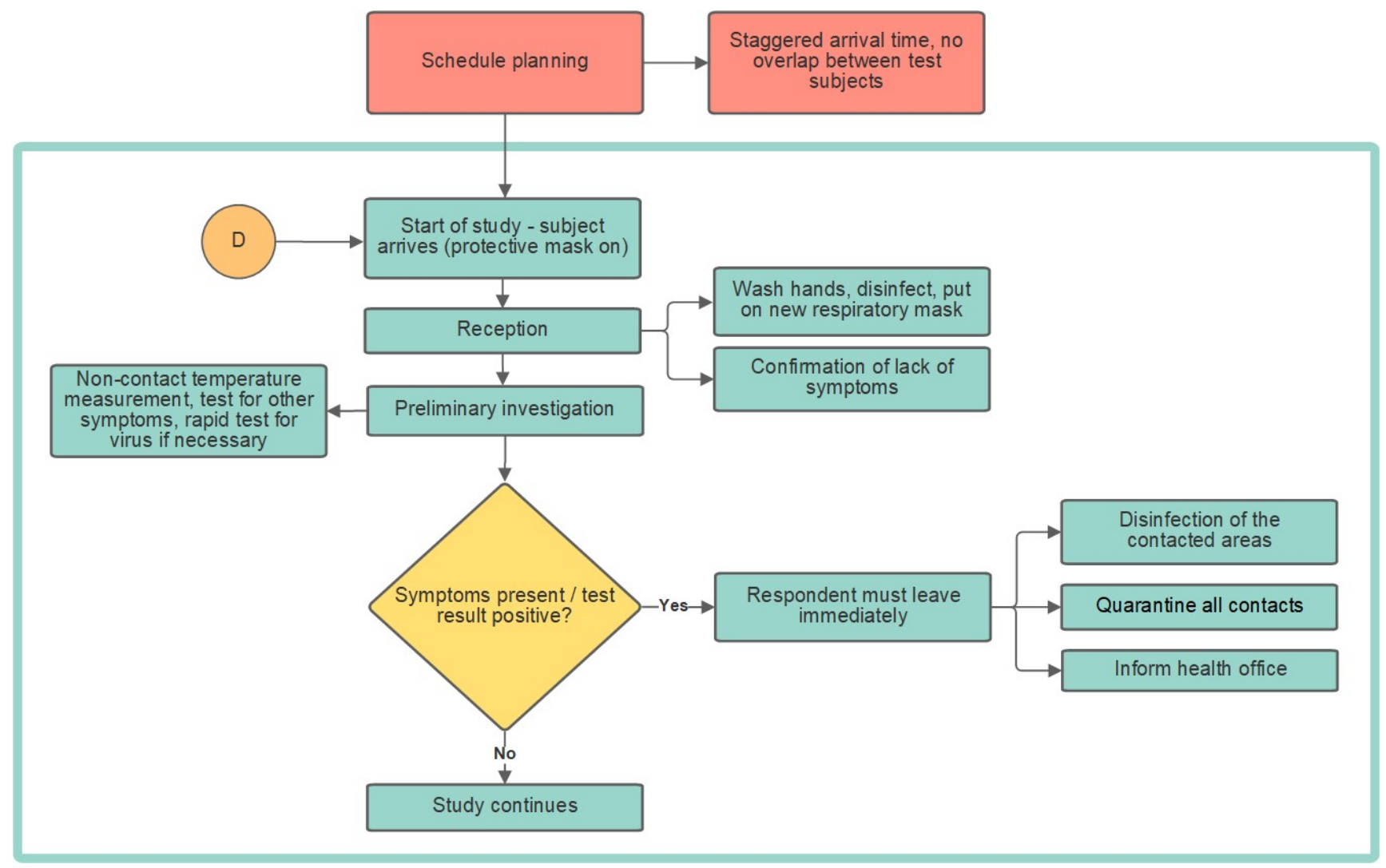

Figure 9. Planning of the schedule and study procedure.

\subsubsection{Planning of test times}

The planning of the individual test times must be done in advance (Figure 9). The goal should be that only one test subject arrives at a given time. Therefore, the duration of the test subject's visit (from reception to discharge) should be determined through a dry run. On the basis of this time, individual subjects can then be assigned appointments for arrival, with which subject overlap is avoided. In effect, the arrival of a subject is always scheduled after the previous participant has left the premises.

\subsubsection{Reception}

The test subjects first go to reception and then the hygiene station. They must first sign a declaration that they are symptom-free. This is intended to prevent someone with pathogen-specific symptoms from participating in the study, but at a minimum, it serves as a legal safeguard for the trial management. 
Subsequently, the subject will be given a new mask that meets at least the FFP2 standard. The subject must wear the mask to ensure the best possible protection for themselves and others during the study. Test subjects should be forbidden from using their own masks, as these may not meet the required standard or may have been worn for too long. It is important that the mask gets put on only after the subject has washed and disinfected their hands. For this purpose, the subject must be instructed on the correct hand washing and disinfection procedures. The test administration must ensure a sufficient safe distance from the subject at all times. As there should only be two people present in the room, the test administrator can maintain a safe distance even if the test subject carelessly moves towards them. If such a situation arises, the subject must be informed immediately about the need to maintain a safe distance. The test administration should ensure that the subjects work quickly so that the time they spend in the room can be reduced.

\subsubsection{Preliminary investigation}

After successfully implementing the hygienic measures, the participants proceed directly to the preliminary examination, where they must continue to be correctly masked and maintain a safe distance. This exam involves being checked for infection-specific symptoms. During the SARS-CoV-2 pandemic, for example, the body temperature of the volunteers should be measured, as fever is a common symptom of COVID-19. This is best done in a non-contact manner using infrared thermometers. COVID-19 affects the sense of smell, a loss of which can be ascertained through a smell test.

If the participant is symptom-free, a rapid test (if applicable) for the virus is carried out at this point. Until the test result is available, the patient must go to the waiting area. If the test result is positive or if the test person exhibits symptoms specific to the infection, the health department must be informed immediately of the possible infection. In addition, all persons who have had contact with this subject must be quarantined. The reception, hygiene station, waiting areas and the pre-examination room must all be completely disinfected afterwards. If the test result is negative and no infection-specific symptoms are present, the actual study can begin.

\subsubsection{During the experiment}

After a successful preliminary examination, the subjects move on to the vehicle or room for the study. If this requires the subjects to wear equipment, such as eye tracking glasses, the investigator must explain to the subjects how to put on the equipment themselves, since the administration cannot do this for them while maintaining a safe distance. Ideally, this should already be done in the waiting area. The test persons must first enter the vehicle or the simulator with the mask on. If the study must be done maskless, it should only be removed immediately before the start of the test. Furthermore, the ventilation settings should not be adjustable so that suboptimal conditions are avoided. When the vehicle is safely parked and the test complete, the subject must immediately put the mask back on. If the test is conducted in a simulator, the subject must not exit the vehicle unmasked. Upon exiting the vehicle or simulator, the subject can remove the equipment and be released from the study. Both the equipment and vehicle must then be disinfected so that they can be used safely by the next person.

\subsection{Disinfection}

When disinfecting the stationary room or the study vehicle (Figure 10), all affected surfaces must be treated with a disposable wipe soaked in degreasing cleaner or soapy water. The wipe must not be reused. Before starting the disinfection, the room or vehicle should be ventilated for 10 minutes by opening all doors and windows. The person performing the disinfection must wear a mask and disposable gloves during the entire disinfection process. The gloves must be disposed of after the disinfection process. 


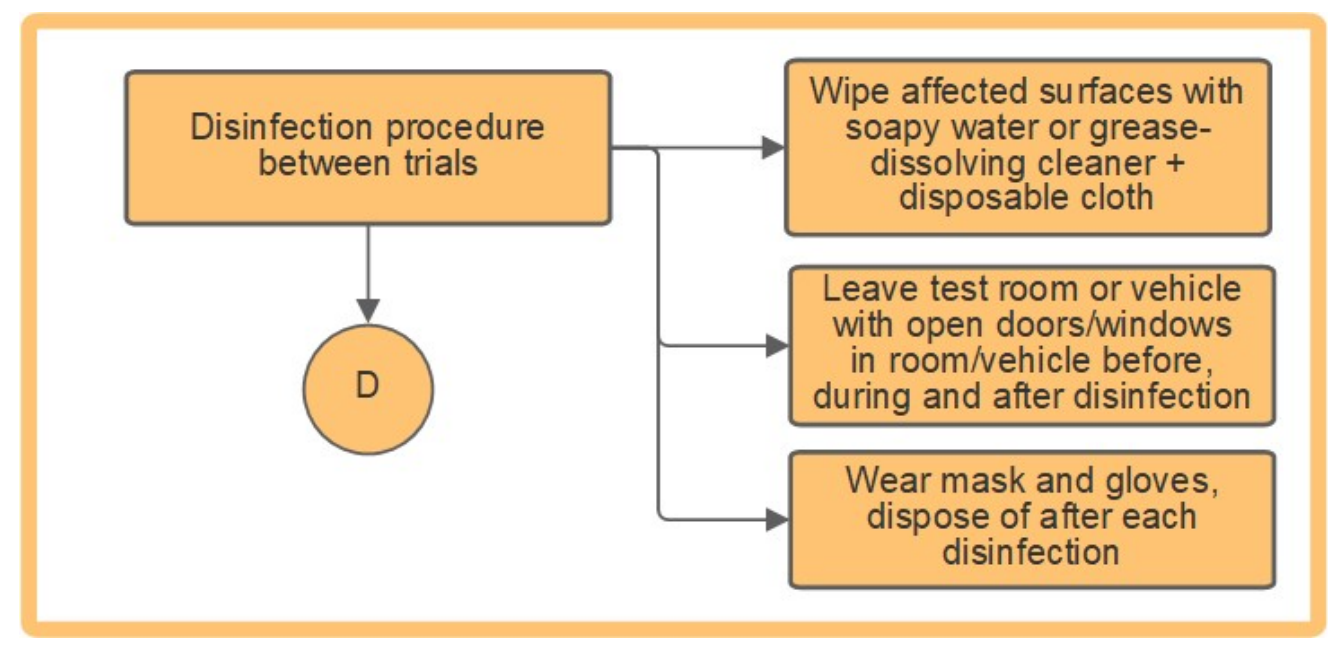

Figure 10. Disinfection of the experimental environment.

The entire procedure must be performed after each trial in order to reduce the risk of infection for the subsequent subject.

\section{Discussion}

\subsection{General}

Pathogens such as the SARS-CoV-2 complicate the ability to do studies as aerosol and droplet core transmission are made possible by the dissemination in a room via air movements. Since the interior of vehicles is likely a small space, aerogenic infections are quite possible without infection protection measures, given a high concentration of aerosols and droplet cores, which can be inhaled. However, since several participants and experimental runs are required to carry out such studies, direct and indirect contact infections as well as via droplets must be prevented.

The holistic concept listed has been developed through the example of the COVID-19 pandemic, but the individual sections can also be applied to other situations such as a flu epidemic, where infection protection measures are appropriate. Situational adjustments to the concept may be required.

\subsection{Evaluation of the pandemic situation}

Due to the changing dynamics of a pandemic, the conditions at the time of the study must always be taken into account and integrated into the evaluation. As weather conditions can change over the course of longer-lasting studies, a further extensive evaluation of the pandemic situation may be required especially when a study begins e.g. in summer and extends into winter. This evaluation should in principle continue beyond the start of a study, in order to evaluate whether it is responsible to continue a study even as a pandemic situation worsens. The indicators should be considered together in this context, as it will provide a holistic picture of the situation. Ideally, testing or vaccination developments during a pandemic can positively impact the feasibility of a study. These advancements should be integrated into any study, where possible, to reduce the risk of infection.

\subsection{Study setting -stationary test rooms}

If studies are conducted indoors, the room-specific conditions must be observed. The concept shows how to reduce the risk of infection, but it must be adapted to the available space. In particular, ventilation conditions are crucial as infection can occur despite social distancing indoors [4]. Fans and suction systems that move air laterally should not be used, as this can actually increase the risk of infection via aerosols and 
droplet cores [37]. The amount of time an individual is in the room should be kept at a minimum [20]. This is of particular importance in smaller rooms.

If the available space is dissimilar from the concept, the risk of infection in the study-specific case can be reduced through the division of the testing areas. Markings help maintain a $1.5 \mathrm{~m}$ distance between individuals. This is only relevant, however if the paths between stations cross and the room planning in Figure 4 is impossible. During the study, occupancy of the test site should be kept to a minimum to further reduce the infection risk.

\subsection{Study setting - vehicle}

Studies conducted in vehicles are a more challenging case as they offer a smaller space where a diagonal seating arrangement must be employed for a maximum of two individuals to be spaced safely more than 1.5 $\mathrm{m}$ apart. The use of a partition further reduces the risk of infection. In most cases, the dividers are not airtight and therefore, only prevent droplet infections and not aerogenic infections because the air and viruscontaining particles can flow around the protective walls [8]. Partitions do significantly slow down the distribution of aerosols and droplet cores in the vehicle [29].

The air exchange rates similarly play an important role in smaller spaces like a vehicle. Opening the car windows as the weather allows should complement the operation of the ventilation as an infection protection measure. The use of the air circulation on the other hand is not recommended, since it would block out fresh air and aerosols and droplet cores are not removed leaving occupants at heightened risk of infection [38].

\subsection{Subject selection}

When selecting subjects, those who are vulnerable and part of at risk groups should be avoided. If absolutely necessary, these individuals can participate provided their risk of infection can be reduced through comprehensive testing including a rapid test at the study start. It should be noted that a less representative statistical distribution of the total population risks the quality of the study outcome even when populations are excluded for reasons of safety.

\subsection{Conducting the study}

Studies occurring during a pandemic, require unnecessary encounters to be avoided. Arrival times for subjects, for instance should be staggered and reception and pre-examination areas must be prepared. The participating subjects must be informed about hygienic measures. Throughout the study, adherence to the respiratory mask, social distancing and hygiene mandates are required. Preliminary examinations shall test subjects for symptoms, the virus or even potentially antibodies in order to prevent infected people from particpating. Since rapid tests in particular are only a snapshot and can be less accurate than PCR tests, caution is required. That's why a positive rapid test needs to be confirmed by a PCR test [39]. The offsetting of participant arrivals also creates clarity made possible by good organization. These positive characteristics are also worthwhile for studies not occurring in the midst of a pandemic.

\subsection{Disinfection}

After each trial, disinfection is required to protect the next subject from a possible infection. Disinfecting wipes are used to prevent indirect contact infections, and ventilation prevents aerogenic infections. When disinfecting, gloves and respiratory masks must be worn. The use of trained cleaning personnel for this task should be discussed. This should not be mandatory, as the disinfection process is relatively easy and straight forward. Furthermore, there are different types of disinfection. For vehicles, wiping disinfection with soapy water is suitable, as it can reach vehicle contours. Other disinfection strategies like physical or thermal ones are available, but they are more complicated to employ. Frequent chemical disinfection can damage vehicle surfaces, which can result in a loss of value. This is particularly important when working with rented vehicles. It is, however more important that hygienic conditions are maintained. Even outside of pandemics, 
viral and bacterial infections are always possible and therefore should be avoided through hygienic measures.

\subsection{Future work}

In addition to this qualitative concept, a quantitative tool would further aid in a robust risk assessment of conducting studies during pandemics. For instance, a numerical maximum threshold could determine when a study must be cancelled or postponed. This value could be calculated through weighting different factors of infection transmission and indicators of pandemic development. The goal of this would be to help test administration confidently decide whether a study can be safely and responsibly conducted under certain difficult circumstances.

\section{Conclusions}

The research review and the resulting concept show that subject studies during a pandemic are feasible, depending on the transmission path of the pathogen. Particular emphasis should be placed on contact avoidance, maintaining a safe distance and respiratory mask wearing. Additionally, optimal ventilation conditions and thorough hygiene is paramount at all times. The explained concept can reduce the risk of infection during test-trial studies, but no infection protection measure provides $100 \%$ safety, so there is always a residual infection risk.

Author Contributions: Conceptualization, A.S. and T.K.; methodology, A.S., T.K. and S.M.; software, A.S. and T.K.; validation, A.S., T.K. and S.M.; formal analysis, A.S. and T.K..; investigation, A.S.; resources, A.S.; writing-original draft preparation, T.K. and A.S.; writing-review and editing, T.K. A.S. and S.M.; visualization, A.S. and T.K.; supervision, T.K.; funding acquisition, T.K. All authors have read and agreed to the published version of the manuscript.

Funding: We acknowledge support by the German Research Foundation and the Open Access Publication Fund of TU Berlin.

Acknowledgments: We thank William Zirkle for language editing. The concept shown here is the result of a recent bachelor's thesis by A.S., which contains the long version of this paper.

Conflicts of Interest: The authors declare no conflict of interest. The results, opinions and conclusions expressed in this paper are not necessarily those of Volkswagen Aktiengesellschaft.

\section{References}

1. Deutschland. Die Timeline zum Coronavirus in Deutschland: Hier findet ihr die wichtigsten Entwicklungen zu Covid-19 in Deutschland im Überblick. Available online: https://www.deutschland.de/de/die-timeline-coronavirus-germany-deutschland (accessed on 11 March 2021).

2. World Health Organization (WHO). Listings of WHO's response to COVID-19. Available online: https://www.who.int/news/item/29-06-2020-covidtimeline (accessed on 12 March 2021).

3. Robert Koch Institut (RKI). Coronavirus SARS-CoV-2: Informationen zur Ausweisung internationaler Risikogebiete durch das Auswärtige Amt, BMG und BMI. Available online:

https://www.rki.de/DE/Content/InfAZ/N/Neuartiges_Coronavirus/Risikogebiete_neu.html (accessed on 12 March 2021).

4. Schulze-Röbbecke, R.; Reska, M.; Lemmen, S. Welche Schutzmaske schützt vor COVID-19?: Was ist evidenzbasiert? Krankenhaushygiene up2date 2020, 15, 123-132, doi:10.1055/a-1133-2046.

5. Leclair, N. Infektionswege. Available online: https://www.teleclinic.com/wiki/infektionswege/ (accessed on 12 March 2021).

6. Helmholtz Zentrum für Infektionsforschung (HZI). Kontaktinfektion. Available online: https://www.helmholtzhzi.de/de/wissen/glossar/entry/kontaktinfektion/ (accessed on 12 March 2021).

7. Asadi, S.; Wexler, A.S.; Cappa, C.D.; Barreda, S.; Bouvier, N.M.; Ristenpart, W.D. Aerosol emission and superemission during human speech increase with voice loudness. Sci. Rep. 2019, 9, 2348, doi:10.1038/s41598-019-38808-z.

8. Kriegel, M. FAQ zu Aersolen in Bezug auf SARS-CoV-2: Dauerlüften, Luftfilter - wie umgehen mit den Aerosolen in Innenräumen? Available online: https://www.tu.berlin/forschen/themenportal-forschen/2020/august/faq-zu-aersolen-inbezug-auf-sars-cov-2/ (accessed on 12 March 2021). 
9. Robert Koch Institut (RKI). Epidemiologischer Steckbrief zu SARS-CoV-2 und COVID-19. Available online: https://www.rki.de/DE/Content/InfAZ/N/Neuartiges Coronavirus/Steckbrief.html;jsessionid=A26AFC1E37AB7F14D92A2947 9166C41F.internet121?nn=2386228 (accessed on 12 March 2021).

10. He, X.; Lau, E.H.Y.; Wu, P.; Deng, X.; Wang, J.; Hao, X.; Lau, Y.C.; Wong, J.Y.; Guan, Y.; Tan, X.; et al. Temporal dynamics in viral shedding and transmissibility of COVID-19. Nat. Med. 2020, 26, 672-675, doi:10.1038/s41591-020-0869-5.

11. Robert Koch Institut (RKI). Coronavirus SARS-CoV-2: Informationen und Hilfestellungen für Personen mit einem höheren Risiko für einen schweren COVID-19-Krankheitsverlauf. Available online: https://www.rki.de/DE/Content/InfAZ/N/Neuartiges_Coronavirus/Risikogruppen.html (accessed on 12 March 2021).

12. Heinrich, C.; Collin, C. Corona-Nachweis: Die Testverfahren im Überblick. Available online: https://www.apothekenumschau.de/krankheiten-symptome/infektionskrankheiten/coronavirus/corona-nachweis-die-testverfahren-im-ueberblick724147.html\#PCR-Schnelltest- (accessed on 12 March 2021).

13. Infektionskrankheiten: verstehen, erkennen, behandeln; Suttorp, N., Ed.; Thieme: Stuttgart, New York, 2004, ISBN 9783131877116.

14. Robert Koch Institut (RKI). Navigation: Virus und Epidemiologie. Available online: https://www.rki.de/SharedDocs/FAQ/NCOV2019/FAQ Liste Epidemiologie.html (accessed on 12 March 2021).

15. Bundeszentrale für Gesundheitliche Aufklärung (BZgA). Abstand halten. Available online: https://www.infektionsschutz.de/coronavirus/alltag-in-zeiten-von-corona/abstandhalten.html\#:\%7E:text=Achten\%20Sie \%20im\%20\%C3\%B6ffentlichen \%20Raum,Sie $\% 20$ auf $\% 20 H \%$ C3\%A4ndesch\%C3\%BCtteln \%20oder\%20Umarmungen (accessed on 11 March 2021).

16. Xie, X.; Li, Y.; Chwang, A.T.Y.; Ho, P.L.; Seto, W.H. How far droplets can move in indoor environments--revisiting the Wells evaporation-falling curve. Indoor Air 2007, 17, 211-225, doi:10.1111/j.1600-0668.2007.00469.x.

17. Bundeszentrale für Gesundheitliche Aufklärung (BZgA). Im Alltag Maske tragen. Available online: https://www.infektionsschutz.de/coronavirus/alltag-in-zeiten-von-corona/im-alltag-maske-tragen.html (accessed on 11 March 2021).

18. Bundesinstitut für Arzneimittel und Medizinprodukte (BfArM). Hinweise des BfArM zur Verwendung von Mund-NasenBedeckungen, medizinischen Gesichtsmasken sowie partikelfiltrierenden Halbmasken (FFP-Masken). Available online: https://www.bfarm.de/SharedDocs/Risikoinformationen/Medizinprodukte/DE/schutzmasken.html (accessed on $11 \mathrm{March}$ 2021).

19. Berufsgenossenschaft für Gesundheitsdienst und Wohlfahrtspflege (BGW). Medizinische Gesichtsmaske - Mund-NasenSchutz (MNS). Available online: https://www.bgw-online.de/DE/ArbeitssicherheitGesundheitsschutz/Hygiene_und_Infektionsschutz/Masken/Maske-02_Mund-Nasen-Schutz.html (accessed on 11 March 2021).

20. Kriegel, M. Anzahl der mit SARS-CoV-2 beladenen Partikel in der Raumluft und deren eingeatmete Menge, sowie die Bewertung des Infektionsrisikos, sich darüber mit Covid-19 anzustecken, 2020. Available online: https://depositonce.tuberlin.de/bitstream/11303/11767.3/9/Virenbeladene_Partikel_im_Raum_v3.pdf.

21. Kriegel, M.; Hartmann, A. Covid-19 Ansteckung über Aerosolpartikel: Vergleichende Bewertung von Innenräumen hinsichtlich des situationsbedingten R-Wertes, 2021. Available online: https://depositonce.tu-

berlin.de/bitstream/11303/12578/5/kriegel hartmann 2021.pdf.

22. Paschotta, R. Luftwechselrate. Available online: https://www.energie-

lexikon.info/luftwechselrate.html\#:\%7E:text=Die\%20Luftwechselrate $\% 20$ eines $\% 20$ Raums $\% 20$ oder, $\% 2$ Fh\%20\%3D $\% 20 \mathrm{~h} \%$ E2\%8 $\underline{8 \% 921}$ (accessed on 12 March 2021).

23. Bundeszentrale für Gesundheitliche Aufklärung (BZgA). Hygiene beachten. Available online: https://www.infektionsschutz.de/coronavirus/alltag-in-zeiten-von-corona/hygiene-beachten.html (accessed on 11 March 2021).

24. Eggers, M.; Terletskaia-Ladwig, E.; Enders, M. Wie wirksam ist Händewaschen gegen Influenzaviren? Hyg Med 2009, 34, 492498.

25. Meyer, B.; Göhring, N.; Wishart, E. Der Beitrag der Flächendesinfektion zur Infektionsprophylaxe im Gesundheitswesen. Hyg Med 2015, 40, 188-191.

26. BG-Verkehr. Taxi. Available online: https://www.bg-verkehr.de/coronavirus/tipps-fuer-unternehmen-und-ihrebeschaeftigten/taxi (accessed on 11 March 2021).

27. Robert Koch Institut (RKI). Coronavirus SARS-CoV-2: Kontaktpersonen-Nachverfolgung bei SARS-CoV-2-Infektionen. Available online: https://www.rki.de/DE/Content/InfAZ/N/Neuartiges_Coronavirus/Kontaktperson/Management.html;jsessionid=95FC0F9AA 93C6588E462C737A5D90BD5.internet061\#a1 (accessed on 12 March 2021).

28. Makoto, T. Prediction and Countermeasures for Infection by Virus Contaminated Droplet in Indoor Environment. Available online: https://www.covid19-ai.jp/en-us/organization/riken/articles/article003 (accessed on 12 March 2021).

29. Makoto, T. Prediction and Countermeasures for Infection by Virus Contaminated Droplet in Indoor Environment. Available online: https://www.covid19-ai.jp/en-us/organization/riken/articles/article004 (accessed on 12 March 2021).

30. Pischinger, S.; Seiffert, U. Vieweg Handbuch Kraftfahrzeugtechnik; Springer Fachmedien Wiesbaden: Wiesbaden, 2016, ISBN 9783-658-09527-7. 
31. Sinanovic, A. Durchführung von Probandenstudien während der COVID-19 Pandemie. Bachelorarbeit; Technische Universität Berlin, Berlin, 2021.

32. Mathai, V.; Das, A.; Bailey, J.A.; Breuer, K. Airflows inside passenger cars and implications for airborne disease transmission. Sci. Adv. 2021, 7, doi:10.1126/sciadv.abe0166.

33. Fruin, S.A.; Hudda, N.; Sioutas, C.; Delfino, R.J. Predictive model for vehicle air exchange rates based on a large, representative sample. Environ. Sci. Technol. 2011, 45, 3569-3575, doi:10.1021/es103897u.

34. Knibbs, L.D.; Morawska, L.; Bell, S.C. The risk of airborne influenza transmission in passenger cars. Epidemiol. Infect. 2012, 140, 474-478, doi:10.1017/S0950268811000835.

35. Robert Koch Institut (RKI). Warum treten Grippewellen immer im Winter auf? Available online: https://www.rki.de/SharedDocs/FAQ/Influenza/FAQ02.html (accessed on 27 April 2021).

36. Bundeszentrale für Gesundheitliche Aufklärung (BZgA). Regelmäßig lüften. Available online: https://www.infektionsschutz.de/coronavirus/alltag-in-zeiten-von-corona/regelmaessig-lueften.html (accessed on 11 March 2021).

37. Kähler, C.; Hain, R. Musizieren während der Pandemie -was rät die Wissenschaft?: Über Infektionsrisiken beim Chorsingen und Musizieren mit Blasinstrumenten, 2020.

38. Ott, W.; Klepeis, N.; Switzer, P. Air change rates of motor vehicles and in-vehicle pollutant concentrations from secondhand smoke. J. Expo. Sci. Environ. Epidemiol. 2008, 18, 312-325, doi:10.1038/sj.jes.7500601.

39. Seifried, J.; Böttcher, S.; Kleist, M. von; Jenny, M.A.; Antão, E.; Oh, D.Y.; Jung-Sendzik, T.; Broich, K.; Denkinger, C.; Bartenschlager, T.; et al. Antigentests als ergänzendes Instrument in der Pandemiebekämpfung. Epidemiologisches Bulletin 2021, 3-14, doi:10.25646/8264. 